\title{
The Etiological Spectrum of Obstructive Jaundice \& Role of Ercp In Thi-Qar Governorate
}

\author{
${ }^{1,}$ Dr. Ali Nayyef Assi,${ }^{2}$,Dr. Alaa Jamel Hassan, ${ }^{3,}$ Dr. Kamal Naeem Ali \\ ${ }_{1,2},((C . A . B . S)$ Thiqar medical college-lecturer \\ ${ }^{3}$, F.I.C.M.S) general surgeon- Thiqar general hospital
}

\begin{abstract}
Obstructive jaundice (o.j) is common surgical problem that occurs when there is an obstruction to the passage of conjugated bilirubin from liver cells to intestine \& one of challenging conditions managed by general surgeons and contribute significantly to high morbidity and mortality. This study was carried out in Al-Hussein teaching hospital, Al-Nissyiria city through 2 years period from December 2010 to November 2012 on 215 patients to assess the incidence of obstructive jaundice, its prevalence according to the causes, , age, sex, places of patients, the curative rate of ercp management \& its complication in our city, 104 (48.3\%) were males and $111(51.6 \%)$ were females, the age ranged from 23 to 80 years, 132 cases (61.3\%) from Thiqar while 83 patients (38.6\%) from other governorates. CBD stone or stones were the most common cause [163 patients $(75.8 \%)], 131$ patients $(80.3 \%)$ of them respond to ERCP treatment
\end{abstract}

Key words: Obstructive jaundice, ERCP

\section{INTRODUCTIONS}

Jaundice refer to yellow discoloration of skin ,sclera and mucous membrane resulting from an increase level of bilirubin concentration in the body fluid ,its detectable when plasma bilirubin exceeds $50 \mathrm{M} \mathrm{mol} / \mathrm{L}$ or 2$3 \mathrm{mg} / \mathrm{dl}$ [1]. Obstructive jaundice (OJ) results from inability of conjugated bilirubin to be secreted into the duodenum due to multifactorial causes ,may be intrahepatic causes (medical jaundice ) as viral hepatitis ,alcoholic hepatitis ,cirrhosis etc. or Extra hepatic biliary obstruction (surgical jaundice) including choledocolithiasis, benign biliary stricture ,intraoperative biliary tract injury or ligation ,cholengiocarcinoma, carcinoma in the head or neck of pancreas ,primary seclarosing cholangitis ,hydatid cyst compression or intrabiliary rupture [2]..(OJ) posses diagnostic and therapeutic challenges to general surgeons and contributes significantly to high morbidity and mortality [3],the challenge is even more conspicuous in a lot of hospitals where delayed presentation of the disease coupled with lack of modern diagnosis (ctscan,ptc.andmrcp) and therapeutic facilities (e.g ERCP ,biliary tract dilator, dormia basket, biliary stents) are among the hall marks of the disease(4). In Ethiopia who report CBD stone was the most common cause of o.j while other studies show carcinoma of head of pancreas was more common than choledocholithaisis(5\&6) parasitic infestation of biliary tract by many parasites mainly are liver flukes (cholonorchis sinensis) called Asiatic cholengiohepatitis . Echinococcus granulouis causing hydaid cyst in the liver or biliary tree causing O.J either by the size of cyst causing pressure effect or by intra biliary rupture and might cause cholangitis.(7)

Studies in Saudi Arabia and yemen reported Ascariasis Lumbricoides to be frequently associated with disease of biliary tract resulting in obstruction[8]. Injury to the biliary tract is not uncommon occur either due to correction of congenital anomalies or difficult open or laparoscopic cholecystectomy due to inadequate surgical training and experience [10], local operative factor increased risk of injury include chronic inflammation, obesity, poor exposure, bleeding obscuring the operative field ,increasing patients age and male gender[11]. Regarding malignant tumor causing obstructive jaundice, gall bladder cancer may presented with right upper quadrant abdominal pain that often mimics other more common biliary and non biliary disorder.[12]. Cholengio carcinoma is uncommon tumor that may occur any where in biliary tree, risk factor for this carcinoma is bile duct stone ,biliary stasis and infection.[13] , cancer of CBD was difficult to differentiate from multiple benign strictures associated with this disorder[14]. Liver metastasis from any part of G.I.T ,or other sites might cause obstructive jaundice by direct extension into perihilar bile ducts. Primary and secondary hepatic tumor may produce obstructive jaundice by metastasis to hilar or pericholedocal L.N[15] . Carcinoma of head of pancreas which is ductal adenocarcinoma represented $80 \%$ of all primary pancreatic cancer ,65\% arise in the head ,neck of pancreas so causing jaundice by obstructing the intra pancreatic portion of common bile duct, patients often got weight loss ,abdominal pain , pruritis, weakness. alteration of bowel habit and anorexia ,the cancer increased with advancing age, black people, male gender and Jewish ethnicity associated with genetic hereditary syndrome [16]. 


\subsection{Aim of study}

To assess the incidence of obstructive jaundice, its prevalence according to the causes, places of patients ,age, sex ,the curative rate of ercp management \& its complication in our city.

\subsection{Patients and methods}

This study was done in Al-Hussein teaching hospital through 2 years from December 2010 to November 2012 on 215 patients ,after complete history, clinical examination . investigation to diagnose the exact cause of O.J. these include tsb-direct \&indirect bilirubin, liver function test, gue, us of the abdomen , mainly for liver and biliary trees, sometime need c.t scan and MRCP after reaching the correct diagnosis we classified patients according to the age, sex, causes, places and we manage them according to their condition whether releasing the obstruction ie removal of stones or palliative treatment by putting a stent .

\section{RESULTS}

During our study a total number(NO) of patients are 215 complaining of obstructive jaundice ,104 (48.3\%) were males and 111(51.6\%) were females, the age ranged from 23 to 80 years. In younger age group up to 30 years females ( 20 cases) were more common than males $(9$ cases), While in age between 71-80 years total NO. were 21 patients [10males \& 11 females] .132 cases $(61.3 \%)$ from Thiqar while 83 patients $(38.6 \%)$ from other governorates. 201 patients $(93.4 \%)$ were benign obstructions and $14(6.5 \%)$ were malignant ones. the commonest causes were CBD stone $163(75.8 \%)$, [91(42.3\%) in females while 72 cases $(33.5 \%)$ were males.] The 2nd cause were hydatid cysts [28(13\%) $15(6.9 \%)$ were females while $13(6 \%)$. were males], either causing pressure on biliary tract or intra biliary rupture of the cyst . Malignant causes of O.J were 14 cases (6.5\%) mostly occur above 50 years old, 10 cases $(4.6 \%)$ in females while 4 cases $(1.9 \%)$ in males .In female7 cases were carcinoma of head of pancreas, 2 cases were cholengio carcinoma of CBD ,one case of gall bladder cancer, while in male all cases were carcinoma of head of pancreas. Post operative CBD strictures or ligations were 10 cases (4.6\%). As CBD stone or stones were the most common cause [163 patients $(75.8 \%)], 131$ patients of them (80.3\%) respond to ERCP treatment and patients become well and discharge with good general condition while 32(19.7) patients showed no response to these treatment either due to difficult canulation of ampulla of vator, incorporative patient or difficult to delivered the stones. In 9 patients a stents were needed, 5 patients were succeeded and 4 patients were failed to put a stents because of difficulty due to tight obstruction and or change in normal anatomy of ampulla of vator because of a sever adhesion due to malignancy.

\section{DISCUSSION}

This study was conducted in Al-Hussein teaching hospital to evaluate the role ERCP in the treatment of obstructive jaundice, to know the the common causes of (OJ) in Thi-qar, gall stones were common problems\& this area was endemic with hydatid diseases and the problem was not previously studied in this governorate. The majority of patients in this study had benign causes [201 cases (93.5\%)] while 14 cases $(6.5 \%)$ were malignant ,the majority of patients with benign causes were choledocholethiasis [163cases(75.8\%)],more common in females [91cases $(42.3 \%)$ ]than males $72(33.5 \%)$, in young age group females were more common than males this result like Bekele et al[4].Total cases of hydatid cyst causing (OJ) were 28 cases (13\%) which was the 2nd commonest cause as hydatid disease is endemic in this area. In our study 10 cases (4.6\%) were due to iatrogenic biliary tree injury ,9 case $(4.1 \%)$ were females and 1 cases in male $(0.5 \%)$. 7 caese of those 10 cases $(70 \%)$ were diagnosed in post operative period and other 3 cases (30\%) discovered intraoperativly .Post operative CBD injury showed a- profuse and persistent bile leak ,or bile peritonitis if no drainage provided. b- deeping or obstructive jaundice when the obstruction is incomplete .The surgical repair determined by using bismuth classification of injury to the biliary tract . Malignant causes of (O.J) were 14 (6.5\%), 10 female cases (4.6\%), 7 cases were carcinoma of the head of pancreas , 2 cases of cholengiocarcinoma \&one case is gall bladder cancer. 4 cases in males (1.9\%), all cases were carcinoma of head of pancreas. About treatment of CBD stone or stones by ERCP ,163 patients presented with obstructive jaundice due to CBD stones. ERCP removal of stones were succeeded in 131 patients (80\%) while 32 patients (20\%), failure rate were due to either difficult to canulation of ampulla of vator, uncooperative patient. so need exploration of CBD by open procedure. 9 patients who had malignancy needed ERCP stent ,5 of those were done successively and 4 patients failed to a put stents .

\section{CONCLUSION}

Obstructive jaundice is a common surgical problem and poses diagnostic and therapeutic challenges, more common among females with gall stones so need study regarding type and the way of processing of food for patients with gall stones to evaluate the exact relation between types of food and occurrence of gall stones, even when removed CBD stone by ERCP procedure there is percentage of patients jaundice might persist due to missed stone or acute and or chronic inflammatory process lead to stenosis of ampulla of vator. acuteand or chronic inflammatory process that occur to the ampulla of vator lead to restenosis , there is some difficulties or 
failed ERCP procedure because of some patients with very stenos ampulla, failed in canullation or incooperate patients also some difficulties in putting a stents in some patients who complained from malignancy because of adhesions or a tight obstruction and they needed open surgery. Hydatid diseases is second commonnest cause of O.J is, so we need to increase the level of education for the community regarding the hydatid cyst its distribution, way of transmition, to decrease the incidence of this disease in our city. Other cause of OJ is iatrogenic due to intraoperative injury of CBD especially by laparoscopic cholecystectomy in newly trained surgeons so need better traning \& education programs. Other cause of O.J is a malignant causes usually occured in old age groups.

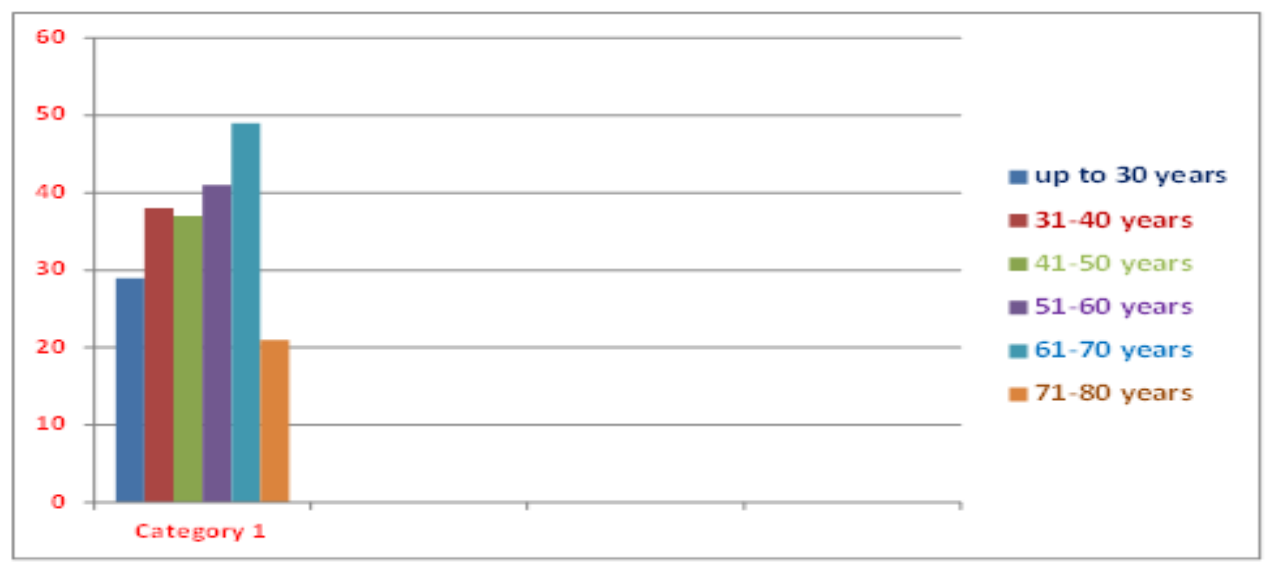

\section{Age distributions of patients with obstructive jaundice}

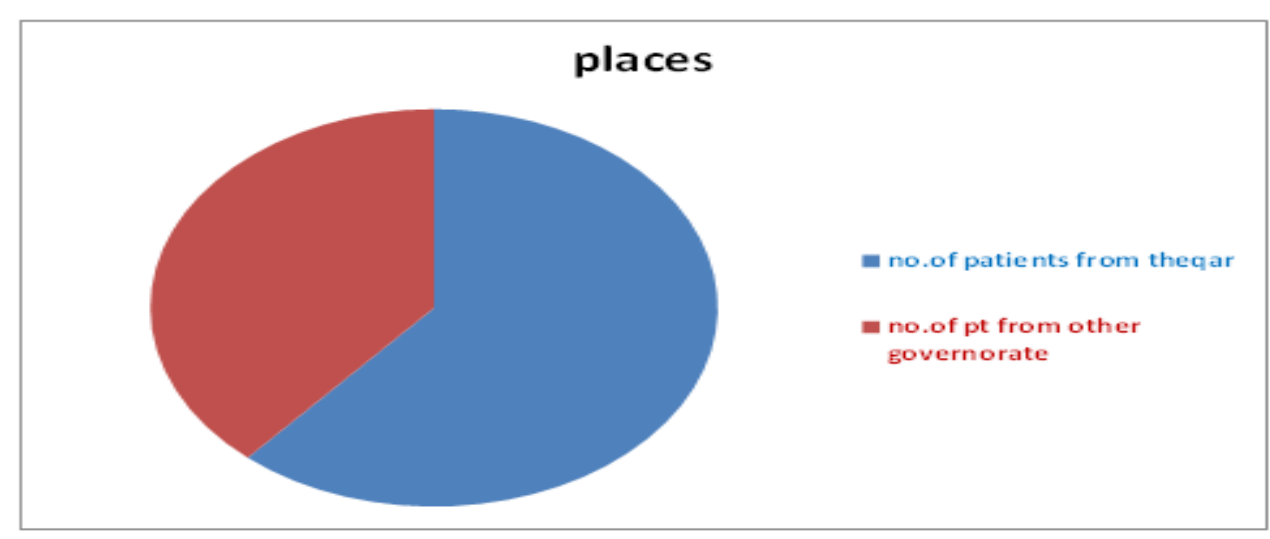

Geographic distribution

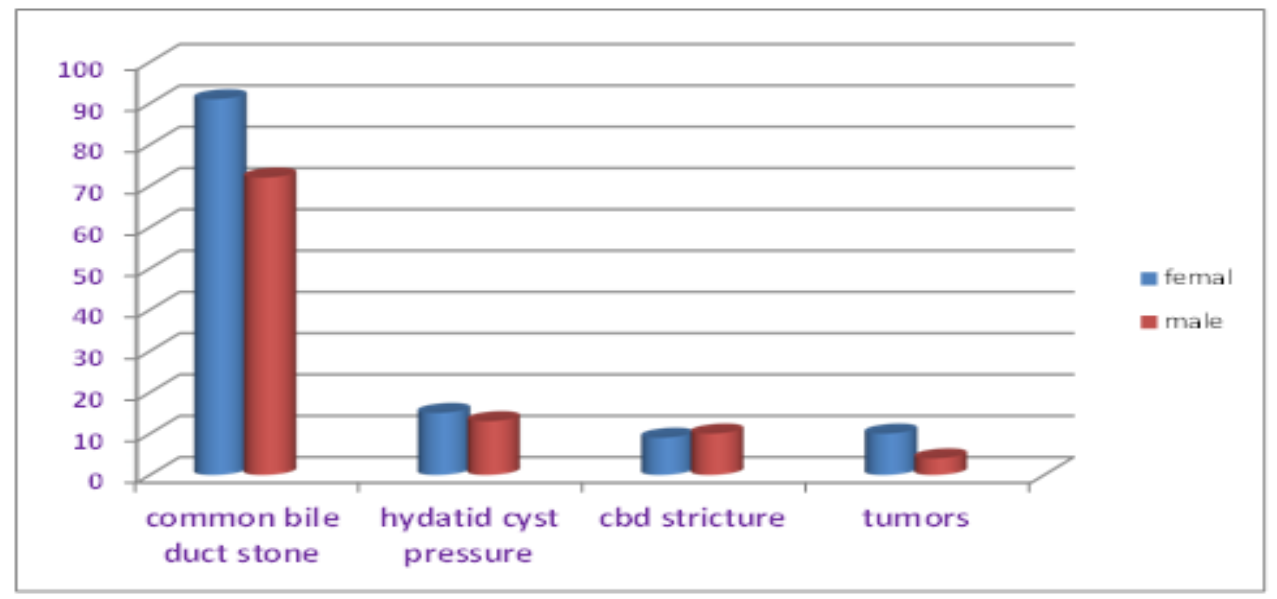

CAUses of obstractive JAUNDice 


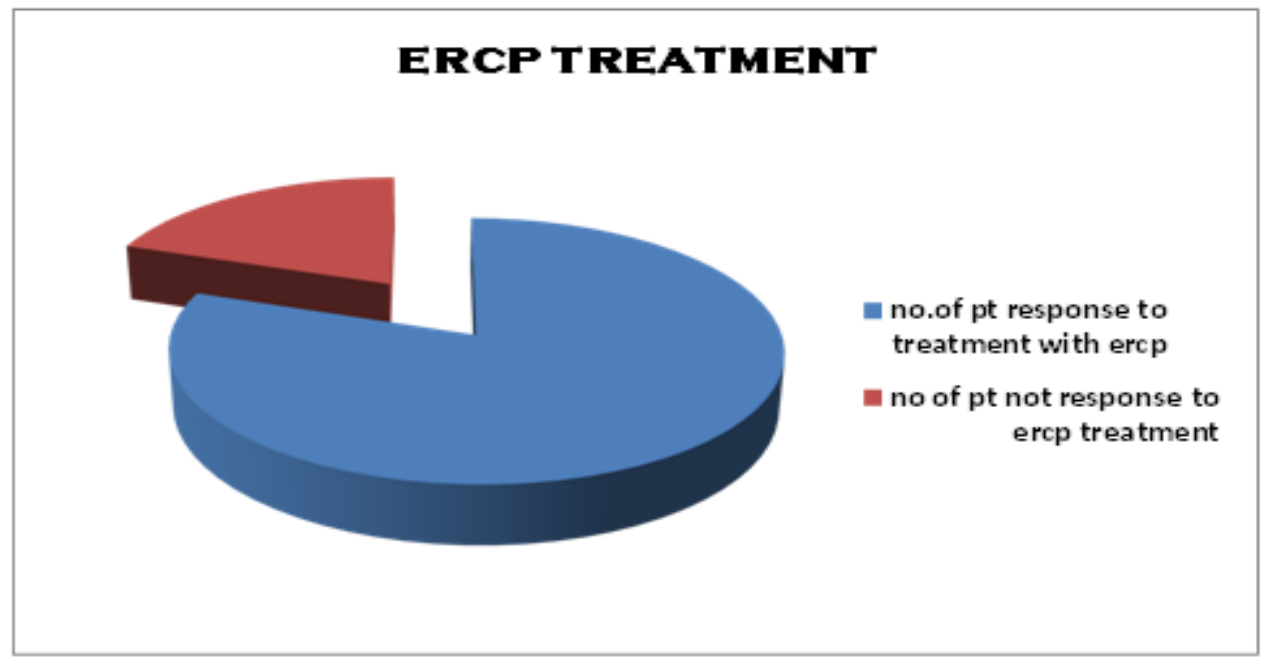

RESPONSE OF PT TO ERCP TREATMENT

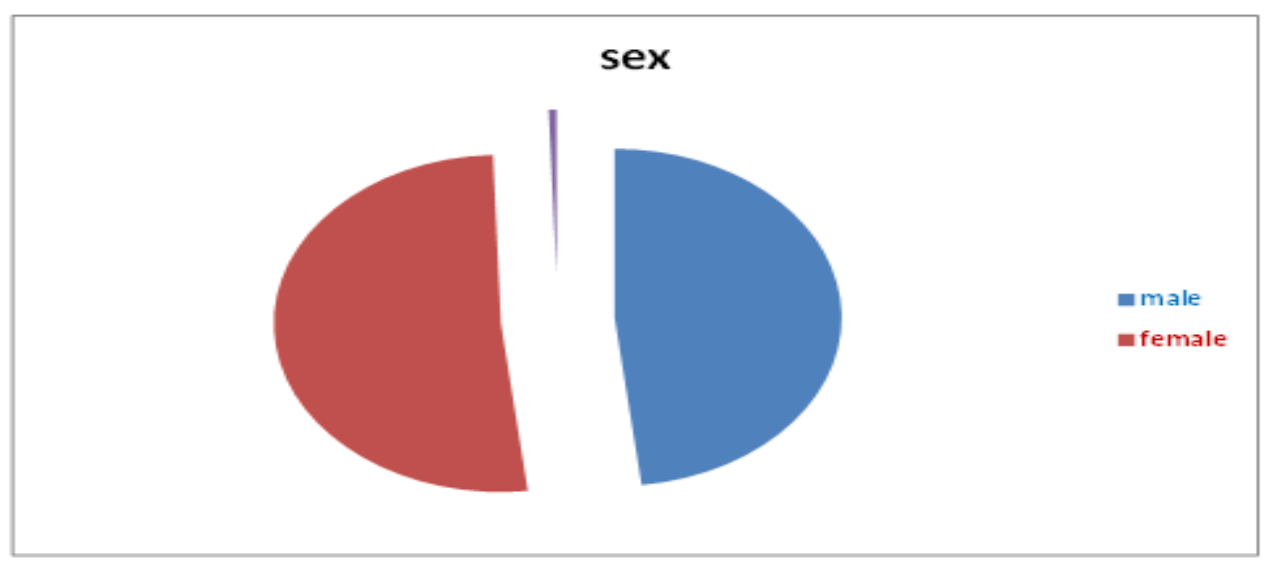

Distributions according to the sex

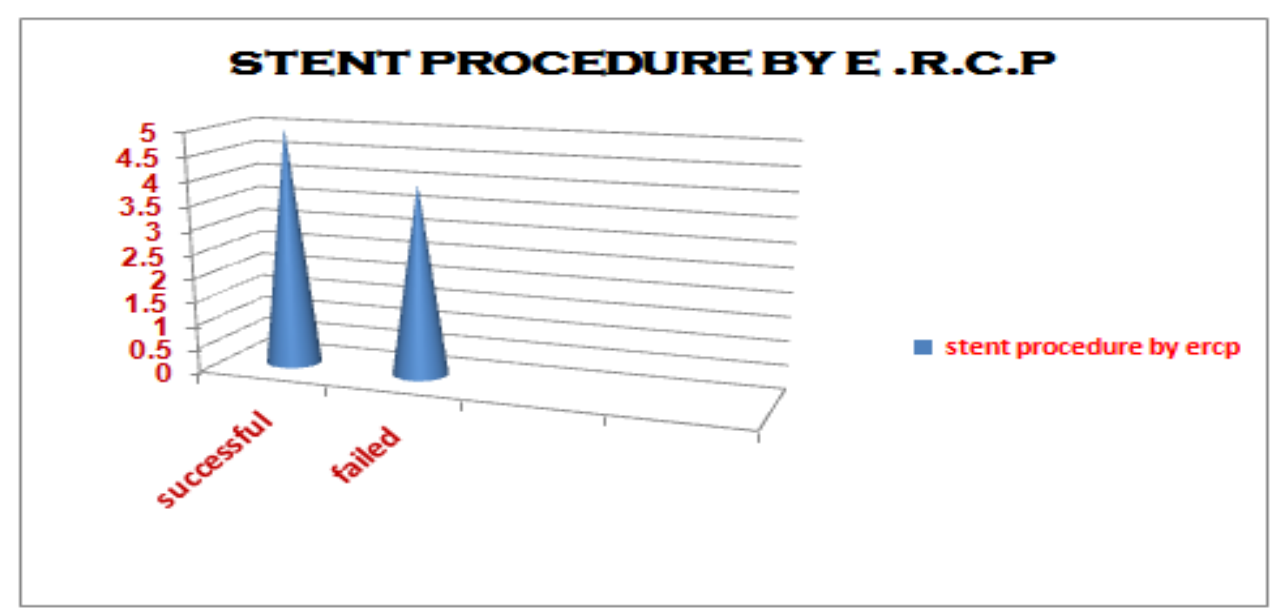

\section{REFERENCES}

[1] davidson's prenciples and practice of medicine edited by Christopher Ha let liver disease page 689 at 1999.

[2] sabiston text book surgery sixteenth edition by john woods harris distinguished chairman department of surgery 2001 page 1080.

[3] Ahmad ,Jan Au,Ahmad R: Obstructive jaundice J.post grad med inst 2001, 15; 194_8.

[4] Bekele Z ,Yafru A ; Obstructive jaundice in adult Ethiopianians in referral hospital Ethiop Med J 2000 ,28:267-75 pub med obstruct.

[5] Khurram S. Qasim A, Shrin M, Aiza J, Aisha E Sarmad L, Asif ZM; Evaluation of aetiological spectrum of obstructive jaundiuce J. Ayub Med Coll Abott 2008,$20 ; 62-66$.pub med abstract. 
[6] Lawal D; Oluwole S ,Makan Joula D, Adekunle M. Diagnosis management and prognosis of obstructive jaundice in lle-life Nigeria.

[7] Baily and Love's short practice of surgery 25th edition Edited by Normans. Williams. 2008 gall bladder and bile ducts page 1127.

[8] Absi MA, Qais AM. Katta MA; Biliary Ascariasis; the value of ultrasound in diagnosis and management in sudia Med 2007. 27; $161--163$ pub Med Abstract published full text.

[9] Farquharson's text book of operative surgery by R.F. Rintol Seventh Edition 1987 page 396.

[10] Adamsen S. Hansen OH. Funch -jensen p. et al Bile duct injury during laparascopic cholecystectomy a prospective nation wide series J. AM. Coll surg. 184; 571.1997.

[11] Branum G, Schmittc. Baillei J.et al management of major biliary complication alter laparascopic cholecystectomy Am. Surg.217532, 1993.

[12] Piehler JM. Crichlow RW.Primary carcinoma of gall bladder surg. Gynicol . Obster.147; 929, 1978.

[13] pitt HA, Dooley WC, Yeo CT,et al Malignancies of biliary tree curr prool surgery 32;1.1995.

[14] Abrendt SA,Pitt HA, Nakeeb Aet al ; Diagnosis and management of cholongio carcinoma in primary sclorosing cholangitis J Gastro inters surg.3; 357- 1999.

[15] Sugiura Y, Nakamura S. Lida et al ,Extensive resection of bile combined with liver resection for cancer of main hepatic duct junction ,A cooperative study of the iceio bile duct cancer study group surgery $115 ; 445,1994$.

[16] Yeo CJ. Cameron JL; pancreatic cancer curr probl surgery 36;57- 152,1999. 